\title{
FLAME ATOMIC ABSORPTION SPECTROMETRIC DETERMINATION OF TRACE AMOUNTS OF SILVER IN RADIOLOGICAL WASTE SAMPLES AFTER SOLID PHASE EXTRACTION USING MULTI-WALLED CARBON NANO-TUBES MODIFIED BY SODIUM DODECYL SULFATE
}

\author{
MOHAMMAD REZA REZAEI KAHKHA ${ }^{1 *}$ AND MASSOUD KAYKHAII \\ Department of Chemistry, Faculty of Sciences, \\ University of Sistan and Baluchestan, Zahedan 98135-674, Iran.
}

\begin{abstract}
Multi-walled carbon nano-tubes was modified with sodium dodecyl sulfate and used as a solid phase extraction adsorbent for the determination of trace silver in radiological waste samples by flame absorption spectrometry. The effects of $\mathrm{pH}$, initial silver ion concentration, sample flow rate and volume, elution conditions and the amount of adsorbent on the recovery of the analyte were investigated and optimized. The results showed that silver could be fully adsorbed at $\mathrm{pH} 7.0$ and eluted by $5.0 \mathrm{~mL} 2 \%$ thiourea in $\mathrm{HNO}_{3}\left(0.1 \mathrm{~mol}^{-\mathrm{L}^{-1}}\right)$. Under the optimized conditions, the adsorption capacity of modified multi-walled carbon nano-tubes was found to be $3.2 \mathrm{mg} . \mathrm{g}^{-1}$ of silver. The detection limit of the proposed method was $350 \mu \mathrm{g}$. $\mathrm{L}^{-1}$ for silver with an enrichment factor of 35 . The relative standard deviation for ten replicate measurement of $0.5 \mu \mathrm{g}$ of silver from $700 \mathrm{~mL}$ samples was $4.7 \%$. The analytical procedure was successfully applied to the determination of trace silver in a few radiological waste samples with the recoveries between $94 \%$ and $105 \%$. Graphite furnace atomic absorption spectrometric technique was also used for the comparison with the suggested method for the determination of the real samples.
\end{abstract}

Key words: Multiwall Carbon Nanotubes; Silver Ion; Radiological Waste; Sodium Dodecyl Sulfate; Solid-Phase Extraction

\section{INTRODUCTION}

Silver is both useful and toxic noble metal which is in-homogeneously distributed in the earth crust, with the average concentration of $80 \mu \mathrm{g} . \mathrm{L}^{-}$ 1 in rocks. ${ }^{1}$ Unfortunately, the silver contamination for environment became a serious problem with the widespread use of silver compounds in different industries such as electronic and electrical applications, dental and pharmaceutical preparations, and manufacturing of fungicides. ${ }^{2} \mathrm{~A}$ small quantity of silver is also usually discharged to the environment via radiological and photographic washing wastes (hypo solution). Thus, developing a sensitive, selective, highly precise, and economical analytical method for the monitoring of silver in environment samples with complex matrices is required. There are many sensitive but expensive analytical methods such as electrochemical analysis, ${ }^{3}$ inductively coupled plasma mass spectrometry ${ }^{4}$ and electrothermal atomic absorption spectrometry. ${ }^{5}$ In addition, these instrumental techniques involve complicated processing step. Flame atomic absorption spectrometry (FAAS) method has the advantage of simplicity and does not need expensive or complicated test equipment; however, direct determination of trace amount of silver by FAAS is not possible due to its low sensitivity. To solve this problem, separation / preconcentration procedure prior to determination by FAAS is a popular choice. Several methods for the preconcentration of silver have been proposed, such as cloud point extraction, ${ }^{5}$ liquid - liquid extraction, ${ }^{6}$ dispersive liquid-liquid microextraction ${ }^{7,8}$ and solid-phase extraction. ${ }^{9-11}$ In comparison with solvent extraction, solid phase extraction (SPE) is superior to trace metals preconcentration due to minimum solvent waste generation, reduction in extraction time and retention of the target species in a more stable chemical form. ${ }^{12}$

Nanomaterials can offer several advantages over traditional SPE sorbents, such as having very high surface areas and a short diffusion route, which results in high extraction capacity and efficiency. ${ }^{13}$ Since the discovery of carbon nanotubes (CNTs) in 1991 by Ijima, ${ }^{14}$ it became clear that they might be an excellent material for SPE because of their high surface area and inner volume, stability and mechanical strength. Therefore, since 1995 the works using diverse types of CNTs as SPE sorbents for metal preconcentration purposes have increased significantly. ${ }^{15,16}$ Beside SPE, some other analytical methods for cations determination are suggested by researchers, of which, modified carbon paste electrode based on multi-walled carbon nanotubes are the most important. ${ }^{17,18}$

The aim of the present study was to develop a sodium dodecyl sulfate (SDS) immobilized on multiwalled carbon nanotubes (MWCNT) to act as SPE sorbents for the determination of Ag in radiological waste. The SPE procedure achieved the elimination of the waste matrix and avoided the need for other sample pretreatment. The capability of the developed method for monitoring silver ions exposure was demonstrated by measuring real radiological waste samples.

\section{MATERIAL AND METHODS}

Instrumental and reagent

A Varian AA 280 FS (model 330, Germany) atomic absorption spectrometer equipped with a silver hollow-cathode lamp and air-acetylene flame was used for all of the absorption measurements. The hollow cathode lamp current was $4.0 \mathrm{~mA}$, the wavelength was set at $328.1 \mathrm{~nm}$, and the slit width was $1.2 \mathrm{~nm}$. The $\mathrm{pH}$ measurements were carried out by a Metrohm $\mathrm{pH}$ meter (model easyseven, Switzerland) using a combined glass-calomel electrode. Silver nitrate (I) and sodium dodecyl sulfate were purchased from Merck KGa (Darmstadt, Germany). Buffer solutions were prepared from 0.5 mol. $\mathrm{L}^{-1}$ acetic acid and 0.5 mol. $\mathrm{L}^{-1}$ sodium acetate for $\mathrm{pH} 4-6$, from $0.1 \mathrm{~mol}^{-\mathrm{L}^{-1}}$ potassium dihydrogen phosphate and 0.1 mol. $\mathrm{L}^{-1}$ disodium hydrogen phosphate for $\mathrm{pH}$ 6-8 and from 0.5 mol. $\mathrm{L}^{-1}$ ammonia and $0.5 \mathrm{~mol} . \mathrm{L}^{-1}$ ammonium acetate for $\mathrm{pH} 8-10$. Untreated MWCNTs (purity $>95 \%$ ) with an average outer diameter of 3-20 $\mathrm{nm}, 1-10 \mu \mathrm{m}$ length, number of walls $3-15$ and surface area of $350 \mathrm{~m}^{2} \cdot \mathrm{g}^{-1}$ were obtained from Plasma Chem GmbH (Berlin, Germany).

\section{Preparation of the Sorbent}

For modification of MWCNTs with SDS surfactant, the following procedure was used: $1 \mathrm{~g}$ of carbon nanotube was dispersed in $400 \mathrm{~mL}$ of acetone and then 0.075 mole of SDS was added to the mixture. This solution was sonicated in an ultrasonic bath for 10 minutes. The obtained suspension was centrifuged at $5000 \mathrm{rpm}$ for 15 minutes and the supernatant phase was discarded. Sedimented phase was separated and dried in $70^{\circ} \mathrm{C}$ for 2 hours and kept in a closed brown bottle for the subsequent use.

\section{Column packing}

A glass column (100 mm in length and $10 \mathrm{~mm}$ in diameter) packed with $0.5 \mathrm{~g}$ of sorbent (height of packing was $10 \mathrm{~mm}$ ) was used as an operational column. For the uniform distribution of liquid, glass beads were placed above the adsorbent and in order to prevent loss of the solid-phase during sample loading, it was blocked by a polypropylene filters at the bottom. For column conditioning, distilled water $(100 \mathrm{ml})$ was passed through the column two times. Ten milliliters of silver ion solution $\left(50 \mu \mathrm{g} \cdot \mathrm{mL}^{-1}\right)$ at $\mathrm{pH} 7.0$ was passed through the column at a flow rate of $1 \mathrm{~mL} \cdot \mathrm{min}^{-1}$. This flow rate was controlled by a valve. The adsorbed silver ion was eluted with $2 \mathrm{M}$ sodium thiosulfate solution with $\mathrm{pH}$ 6. Analyzing silver ion in the effluent was performed using a flame atomic absorption spectrometer. For real sample extraction, a feed reservoir of $2 \mathrm{~L}$ capacity was conducted at the top of the column.

\section{Sample preparation}

Radiological waste samples were collected in acid leached polyethylene bottles. The samples were filtered before analysis through a $0.45 \mu \mathrm{m}$ membrane filter (Millipore) and stored in a polyethylene container for subsequent usage. 


\section{RESULT AND DISCUSSION}

In this study, a step-by-step optimization scheme was used in order to optimize extraction conditions. To evaluate the performance of the proposed methods, the enrichment factor (EF) was calculated using Eq. (1) ${ }^{19}$

$$
\mathrm{EF}=\mathrm{C}_{\mathrm{e}} / \mathrm{C}_{\mathrm{aq}}
$$

Where $\mathrm{EF}, \mathrm{C}_{\mathrm{e}}$ and $\mathrm{C}_{\mathrm{aq}}$ are the enrichment factor, analyte concentration in the extraction solvent and analyte concentration in the sample respectively. In order to calculate the recovery of analyte, the content of silver in the eluent was determined.

\section{Effect of pH}

$\mathrm{pH}$ is one of the important analytical factors in the solid phase extraction of metal ions, ${ }^{20}$ so that the influences of $\mathrm{pH}$ of the aqueous solution on the recovery of $\mathrm{Ag}+$ ions on SDS- MMWCNTs were investigated in the $\mathrm{pH}$ range of 5 to 9.5. The percentage adsorption of $\mathrm{Ag}+$ on the sorbent surface as a function of the $\mathrm{pH}$ of the sample solution is shown in Fig. 1.

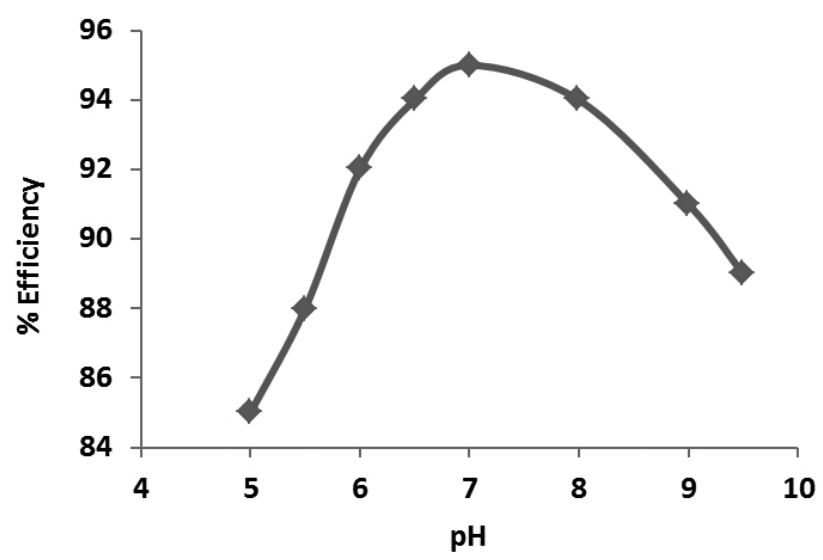

Fig. 1. Effect of $\mathrm{pH}$ on column efficiency (silver eluted by $5.0 \mathrm{~mL}$ of $2 \%$ thiourea in 0.1 mol. $\mathrm{L}^{-1}$ of $\mathrm{HNO}_{3}$ )
At basic $\mathrm{pH}$ values, several metallic analytes can precipitate and so silver could co-precipitate. Around $\mathrm{pH} 7.0$ the extraction efficiency reaches a maximum, and therefore this $\mathrm{pH}$ is considered to be the suitable extraction acidity.

\section{Effect of sample flow rate and nature of the eluent}

The sample flow rate is a measure of the contact time between the sample solution and the sorbent and should be optimized to ensure quantitatively retention along with minimization of the time required for sample processing. The flow rate of the sample solution was studied within the range of $0.5-3$ $\mathrm{mL} \cdot \mathrm{min}^{-1}$. Results showed that the flow rate variation in this range did not have a significant effect on the sorption of the $\mathrm{Ag}^{+}$. It was found that the adsorption of $\mathrm{Ag}^{+}$on SDS-MWCNTs is relatively rapid. In order to achieve better precision, a flow rate of $1 \mathrm{~mL} \cdot \mathrm{min}^{-1}$ was chosen for further studies. In order to obtain a high or achievable pre-concentration factor of very dilute analyte solutions from large volumes, it is imperative to investigate the effect of type and volume of eluent solvent on the retention of analytes on the SDS modified SDSMWCNTs. Various eluent solvents with different concentrations were tested to choose the best solution for the elution of the $\operatorname{Ag}(\mathrm{I})$ ions accumulated on the sorbent, and the percentage recovery for each eluent type was determined. Among the eluents studied, sodium thiosulfate provided higher recovery efficiency compared to other solutions, and the highest recoveries were obtained with $10 \%$ thiosulfate in $0.1 \mathrm{~mol} \cdot \mathrm{L}^{-1} \mathrm{HNO}_{3}$. The effect of the volume on the recovery of selected eluent solution was also investigated. The most quantitative recoveries were found by $20.0 \mathrm{~mL}$ of eluent volume. Therefore, in this study $20.0 \mathrm{~mL}$ of $10 \%(\mathrm{w} / \mathrm{v})$ thiosulfate in $0.1 \mathrm{~mol}^{-\mathrm{L}^{-1}} \mathrm{HNO}_{3}$ solution was chosen for subsequent experiments.

\section{Effect of sample volume}

The sample volume is an important parameter which influences the preconcentration factor. An increase in the ratio of volume of aqueous sample to eluent volume will result in significant increase in the preconcentration factors. Therefore, the effect of sample volume on the recoveries of the analyte ions was investigated by using model solutions containing the same amount of trace $\mathrm{Ag}(\mathrm{I})$ ions in the volume range of $100-1000 \mathrm{~mL}$ which were passed through the column under optimum conditions. The recoveries were found to be stable up to $700 \mathrm{~mL}$ and hence, $700 \mathrm{~mL}$ was chosen as the largest sample volume for further studies. Owing to volume of eluent $(20 \mathrm{~mL})$, preconcentration factor is 35 .

Table 1. Comparison of present method with other SPE methods for the preconcentration of silver ions.

\begin{tabular}{|c|c|c|c|c|c|c|c|}
\hline Sample analyzed & Adsorbent & $\begin{array}{l}\text { Adsorption capacity } \\
\left(\mathrm{mg} \cdot \mathrm{g}^{-1}\right)\end{array}$ & $\mathrm{EF}^{1}$ & $\mathrm{RSD}^{2}(\%)$ & $\begin{array}{c}\mathrm{LOD}^{3}\left(\mathrm{mg} . \mathrm{L}^{-}\right. \\
\left.{ }^{1}\right)\end{array}$ & $\begin{array}{l}\text { Extraction } \\
\text { time (min) }\end{array}$ & Ref \\
\hline Water & MWCNTs & 5.4 & 160 & 2.43 & 0.21 & 10 & 21 \\
\hline Water & n-dodecyltrimethylammonium bromide & $\mathrm{NM}^{4}$ & 37 & 2.1 & 1.1 & 60 & 22 \\
\hline Food & $\begin{array}{c}\mathrm{Fe}_{3} \mathrm{O}_{4} \text { nanoparticles coated with } \\
\text { 3-(trimethoxysilyl)-1-propanethiol and } \\
\text { modified with ethylene glycol bis- } \\
\text { mercaptoacetate }\end{array}$ & 10.4 & 194 & 5.31 & 0.12 & 30 & 23 \\
\hline $\begin{array}{l}\text { Radiology film } \\
\text { and natural water }\end{array}$ & $\begin{array}{l}\text { 2-mercaptobenzothiazole (MBT) on } \\
\text { microcrystalline naphthalen }\end{array}$ & 1.18 & 160 & 1.4 & 0.02 & 60 & 24 \\
\hline Food & $\begin{array}{l}\text { MWCNT modified with } \\
\text { (3-mercaptopropyl) silanetriolate }\end{array}$ & NM & NM & $>4$ & 1.4 & 30 & 25 \\
\hline $\begin{array}{l}\text { Radiological } \\
\text { waste }\end{array}$ & MWCNTs modified with SDS & 3.2 & 35 & 4.7 & 0.35 & 9 & $\begin{array}{l}\text { This } \\
\text { study }\end{array}$ \\
\hline
\end{tabular}

\footnotetext{
${ }^{1}$ Enrichment factor

${ }^{2}$ Relative standard deviation

${ }^{3}$ Detection limit, calculated based on a signal-to-noise ratio of 3 for 11 blank measurements

${ }^{4}$ Not mentioned
} 


\section{Sorbent Capacity and regeneration}

The adsorption capacity is an important factor, because it determines how much sorbent is required to concentrate the analytes from a given solution quantitatively. Adsorption capacity was estimated by passing $100 \mathrm{~mL}$ of 10 $\mathrm{mg} . \mathrm{L}^{-1}$ of silver ion solution onto $100 \mathrm{mg}$ SDS-MWCNT packed in the column. After then, the column was washed with a few $\mathrm{mL}$ of water to be sure of removal of excess $\mathrm{Ag}^{+}$ions. Subsequently the adsorbed ions were eluted with $20.0 \mathrm{~mL}$ of $10 \%(\mathrm{w} / \mathrm{v})$ thiosulfate in $0.1 \mathrm{~mol}^{-\mathrm{L}^{-1}} \mathrm{HNO}$ to ensure full elution and then determined by FAAS. The capacity of SDS-MWCNT for Ag (I) was determined to be $3.2 \mathrm{mg} \cdot \mathrm{g}^{-1}$.

Regeneration is one of the key factors for evaluating the performance of the adsorption material. In this work, it was found that SDS-MWCNT can be reused up to four times without loss of analytical performance. Considering that $5.0 \mathrm{~g}$ of SDS-MWCNT could be prepared in one batch, and only $100 \mathrm{mg}$ of SDS-MWCNT were used for one extraction operation, this reusable time is acceptable.

\section{Reproducibility}

The recommended procedure was repeated 10 times under optimum conditions for a $700 \mathrm{~mL}$ solution containing $0.5 \mathrm{mg}$ of silver to find the relative standard deviation in determination of this ion. The results show that relative standard deviation (RSD) was $4.7 \%$. Comparison of the figures of merit of the suggested method with other SPE methods combined with flame atomic absorption spectrometric for the determination of silver are summarized in Table 1. As can be seen, the limit of detection, reproducibility and preconcentration factor of the suggested method is comparable with what recently reported; however, the extraction time is shorter than the others.

\section{Application of proposed method to real sample}

The proposed method was applied to the determination of silver in three real radiological and photographical samples at optimum condition. The reliability was checked by the recovery experiments. Comparison of the results with the data obtained by means of graphite furnace atomic absorption spectrometry was also done. The results of this investigation are indicated in Table 2. As can be seen, good spike recoveries (94.4-105.2\%) were achieved which indicates that there is no serious interference in recovery of silver ions from a complicated matrix such as radiological waste samples by this extraction method.

Table 2. Applying selected method for the analysis of real samples.

\begin{tabular}{|c|c|c|c|}
\hline Sample & $\begin{array}{c}\text { Added }(\boldsymbol{\mu g} . \\
\left.\mathbf{m L}^{-1}\right)\end{array}$ & $\begin{array}{c}\text { Found }(\boldsymbol{\mu g} . \\
\left.\mathbf{m L}^{-1}\right)\end{array}$ & Recovery (\%) \\
\hline & 0.0 & $4.4 \pm 0.2$ & - \\
Radiological waste & 5.0 & $9.4 \pm 0.2$ & 100.4 \\
& 10.0 & $14.3 \pm 0.3$ & 99.6 \\
\hline & & & \\
Radiological waste & 0.0 & $6.2 \pm 0.1$ & - \\
& 5.0 & $11.3 \pm 0.1$ & 100.8 \\
& 10.0 & $15.4 \pm 0.5$ & 94.4 \\
& & & \\
& & & \\
Photographical waste & 0.0 & $3.7 \pm 0.5$ & - \\
& 5.0 & $9.2 \pm 0.4$ & 105.2 \\
& 10.0 & $13.4 \pm 0.2$ & 97.4 \\
\hline
\end{tabular}

\section{CONCLUSION}

A SPE procedure using SDS-MWCNTs as sorbent material has been developed for the extraction of $\mathrm{Ag}^{+}$from radiological waste samples prior to FAAS determination. Ag (I) ions were retained on SDS-MWCNTs and were successfully desorbed with a thiosulfate solution. A good selectivity of the adsorption phase toward the target analyte was observed. It was found that SDS modified MWCNTs show high adsorption capacity for silver, and the analyte retained on its surface can be easily desorbed. Hence, SDS modified MWCNTs showed great potential as an adsorbent for the preconcentration of trace metal ions such as silver in samples with complicated matrix. The method compares favorably with a reference GFAAS method.

\section{REFERENCES}

1. J. D. Lee, Concise Inorganic Chemistry, $5^{\text {th }}$ Edition (1996), Chapman \& Hall, London 619-621.

2. M. A. Karimi, Z. Mohammadi, A. Mohadesi, A. Hatefi-Mehrjardi, M. Mazloum-Ardakani, L. Sotudehnia Korani, A. Askarpour Kabir, Sci. Iranica Trans. F Nanotechnol., 2011, 18, 790

3. G. Chakrapani, P. L. Mahanta, D. S. R. Murty, B. Gomathy, Talanta, 2011, 53, 1139 .

4. J. Moreda-Piñeiro, E. Alonso-Rodríguez, A. Moreda-Piñeiro, C. MoscosoPérez, S. Muniategui-Lorenzo, P. López-Mahía, D. Prada-Rodríguez, P. Bermejo-Barrera, Anal. Chim. Acta, 2011, 679, 63.

5. H. Tavallali, S. Yazdandoust, M. Yazdandoust, Clean Soil, Air, Water, 2010, 38, 242

6. P. Dey, S. Basu, Int. J. Chem. Tech. Res., 2011, 3, 1349.

7. D. Afzali, A.R. Mohadesi, B. B. Jahromi, Anal. Chim. Acta, 2011, 684, 45.

8. S. Z. Mohammadi, D. Afzali, M. A. Taher, Y. M. Baghelani, Talanta, 2011, 80,875 .

9. M. Sun, J. Feng, Y. Bu, H. Duan, X. Wang, C. Luo, J. Sep. Sci., 2014, 37, 3691.

10. Q. Ding, Qiong Ding Remove suggestion Invite to join ResearchGate Invite Invited P. Liang, Pei Liang Huazhong (Central China) Normal University, Wu-han-shih, Hubei, China Remove suggestion Invite to join ResearchGate Invite Invited F. Song, A. Feng Song Huazhong (Central China) Normal University, Wuhan, Hubei, China Remove suggestion Invite to join ResearchGate Invite Invited Xiang, Sep. Sci. Technol., 2006, 41, 2723.

11. M. G. Pereira, M. A. Z. Arruda, Microchim. Acta, 2003, 141, 115.

12. M. Akhond, G. Absalan, L. Sheikhian, M. Eskandari, M. Sharghi, Sep. Purif. Technol., 2006, 52, 53.

13. Y. Zhang, E. Suhir, C. Gu, Physical Properties and Mechanical Behavior of Carbon Nano-tubes (CNTs) and Carbon Nano-fibers (CNFs) as Thermal Interface Materials (TIMs) for High-Power Integrated Circuit (IC) Packages: Review and Extension in Nano-Bio- Electronic, Photonic and Mems Packaging, C. P. Wong, K. S. Moon, Y. Li, Eds., Springer-Verlag US, 2010, pp 315-347.

14. S. Ijima, Nature, 1991, 354, 56.15. M. Rosa, P. Crecente, C. Gutiérrez Lovera, J. Barciela García, J. Álvarez Méndez, S. García Martín, C. Herrero Latorre, Spectrochim. Acta B, 2014, 101, 15.

16. A. Moghimi, S. A. Hossaini, Orient. J. Chem., 2015, 31 (1), 263.

17. T. A. Ali, G. G. Mohamed, Sens. Actuat. B, 2014, 202, 699.

18. A. R. Ansari Dezfoli, M. A. Mehrabian, H. Hashemipour, Adsorption, 2013, 19, 1253.

19. M. Kaykhaii, S. Noorinejad, J. Anal. At. Spectrom., 2014, 29, 875.

20. M._C. Hennion, J. Chromatogr. A., 1999, 856, 3.

21. P. Biparva, M. R. Hadjmohammad, Clean Soil, Air, Water, 2011, 9, 1081.

22. S. Z. Mohammadi, D. Afzali, Z. Heshmati, Toxicol. Environ. Chem., 2013 , 95, 1299.

23. M. H. Mashhadizadeh, M. Amoli-Diva, M. R. Shapouri, H. Afruzi, Food Chem., 2014, 151, 300.

24. F. Shakerian, AM. Haji Shabani, S. Dadfarnia, M. Shabani, J. Chem., 2013, 2013,465825 .

25. M. Ghaedi, M. Montazerozohori, E. Nazari, R. Nejabat, Hum. Exp. Toxicol. 2013, 32, 687. 